\title{
Power quality enhancement by using D-FACTS systems applied to distributed generation
}

\author{
S. A. Zegnoun ${ }^{1}$, M. N. Tandjaoui ${ }^{2}$, M. Djebbar ${ }^{3}$, C. Benachaiba ${ }^{4}$, B. Mazari $^{5}$ \\ ${ }_{1,3}$ Mohammed Boudiaf University of Science and Technologies, Algeria \\ ${ }^{2,4,5}$ Smart Grid \& Renewable Energy Laboratory, University Tahri Mohamed of Bechar, Algeria
}

\begin{tabular}{l} 
Article Info \\
\hline Article history: \\
Received Jul 17, 2018 \\
Revised Nov 4, 2018 \\
Accepted Nov 18, 2018 \\
\hline
\end{tabular}

\section{Keywords:}

D-FACTS

Distributed generation

Power quality enhancement

Renewable energy

Smart grid

\begin{abstract}
In the majority of the isolated areas, the diesel generator is the principal source of electric power. For these areas, the price of extension of the electrical supply network is prohibitory and the price of fuel increases radically with insulation. The continuous fall in the prices of the generators based on renewable energy and the increasing reliability of these systems led to a greater use of the sources of renewable energy for the generation of electric power in the isolated areas. The diesel generators can incorporate in a network with other sources in base of renewable energies in order to create a new network known as distributed network. More recently intermittent renewable resources such as the wind power were considered as a distributed generation which is seen as being deployed to reduce the total emissions. The distributed generation equipment sets causing electric disturbances result in destabilizing the global network as well as pollutant, for these reason, system D-FACTS comes to answer all the concern of the customers, manufacturers, suppliers and the managers of the distributed network.
\end{abstract}

Copyright (C) 2019 Institute of Advanced Engineering and Science. All rights reserved.

\section{Corresponding Author:}

Si Ahmed Zegnoun, Departement of Electrical, Mohammed Boudiaf University of Science and Technologies, Oran, BP 1505 Bir El Djir 31000 Oran, Algeria.

Email: Zsiddou@gmail.com

\section{INTRODUCTION}

Today over $85 \%$ of energy is obtained from fossil fuels like oil, coal, natural gas or nuclear energy generates a strong environmental pollution discharge greenhouse gas emission that cause irreversible climate change or in the case of nuclear radiation pollution long term that is the problem today unsolved storage of radioactive waste.

Regarding technology systems decentralized energy production; there are currently two types of systems with a strong presence: systems based on renewable energy and cogeneration systems. These systems, encouraged by the government, have become an economically viable reality and are therefore binding of fact.

Renewable energy power systems can be a cost-effective alternative for areas with high electricity connection fees. It is also possible to connect renewable energy power systems to the grid, reducing the amount of electricity you need to purchase, or in some cases, allowing you to export surplus power into the grid. There are many renewable energy sources is shown in Figure 1 such as biomass, solar, wind, hydro, and tidal power [1].

Due to the depletion of fossil energy and environmental contamination, a renewable energy application such as wind system has been widely used for a few decades to supply energy. Generation of electricity using diesel is costly for small remote isolated communities. At remote location electricity 
generation from renewable energy such as wind can help reduce the overall operating costs by reducing the fuel costs.

A wind-diesel hybrid system is any autonomous electricity generating system using wind turbine(s) with diesel generator(s) to obtain a maximum contribution by the intermittent wind resource to the total power produced, while providing continuous high-quality electric power.

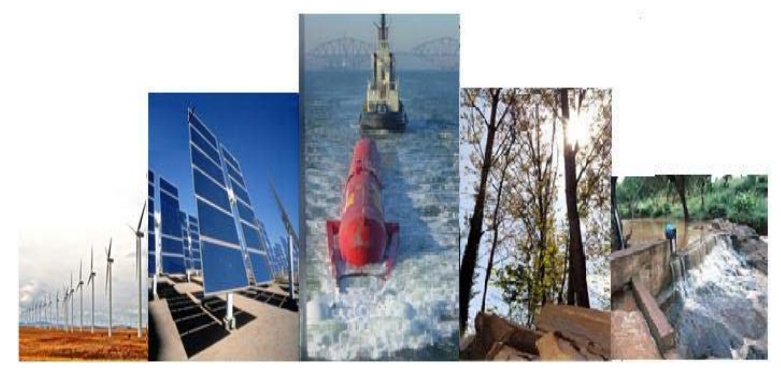

Figure 1. Most sources of renewable energy

The existence of the Wind-Diesel generation system started in the later part of 20th century. The integration of two generating system relies mainly on complex controls to make certain of proper sharing of discontinuous wind energy and handy diesel generation to meet up the demand which usually variable in nature. It is also a major concern to reduce the environmental impact of diesel generation which is advantage of the Hybrid Wind Diesel power generation. However, the penetration of wind power into small dieselbased grids is limited because of its effect on power quality and reliability. Figure 2 presents a schematic diagram of a generalized wind-diesel system [3].

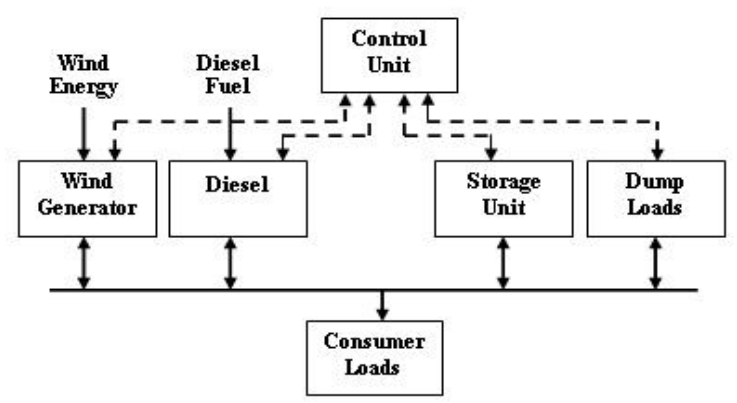

Figure 2. Schematic of generalized wind-diesel system

Our problematic is one of the major challenges in industry today, is power quality problems and sensitive of loads. Presently, the majority of these problems are due to different fault conditions. These later cause voltage disturbance like the apparatus tripping, shutdown commercial, domestic and industrial equipment and miss process of drive system [4].

Voltage sags and over-voltages are principal of the most occurring power quality problems. They occur more often and cause severe problems and economical losses. There are many different methods to compensate these faults, but the use of a custom Power device is considered to be the most efficient method. For example, Distribution Flexible AC Transmission Systems (D-FACTS), based on use of power electronics controllers in a distribution system, specially to deal with various power quality problems [5], [6]. Among these the dynamic voltage restorer (DVR) is the most effective devices both of them based on the voltage source converter (VSC) principle.

This paper focuses on the aim to answer a problem on the stability and power quality at the level of combination of Wind Turbine and Diesel Generator systems embedded D-FACTS systems such a DVR for sustained power generation. Dynamic voltage restorer (DVR) can provide the cost-effective solution to

Power quality enhancement by using d-facts systems applied to distributed generation (S. A. Zegnoun) 
mitigate voltage sag and swell by establishing the appropriate voltage quality level, required by the customer. It is recently being used as the active solution for voltage disturbance mitigation.

\section{PRINCIPAL OPERATION OF HEDS}

The effective and hybrid use of these sources are very essential for the optimized power generation. The main goal with these systems is to reduce fuel consumption and, in this way, to reduce system operating costs and environmental impacts. These fuel consumption savings are maximum with wind-diesel systems with high wind penetration, in which the diesel(s) generators may be shut down during high wind availability.

The transportation cost of the fuel to the remote locations can be limited by effective use of this hybrid system by the optimal operation of the generations together.

The major advantage of WDHS is that it can be operated based on the requirement which is constrained with wind source. The Synchronous machine of Diesel Generation set can be used a synchronous condenser in Wind mode to enable the reactive power compensation of the system without installation of any ancillary equipment which is economic benefit in this type of system. The WDHS is being classified based on the Wind energy penetration level which is defined as (1):

$$
E P=\frac{\text { WTAE output }(\text { Kwh })}{A P E D(\text { Kwh })}
$$

Ep: Energy Penetration

WTAE: Wind Turbine Annual Energy

APED: Annual Primary Energy Demand

The WDHS is classified as low penetration when EP $<20 \%$ and as medium penetration when $20 \%$ $<$ EP 50\%. If the wind generation is capable of shutting down the diesel generation then it is called High Penetration [7]. Hybrid wind-diesel systems with high penetration of wind power have three plant modes: diesel only (DO), wind-diesel (WD) and wind only (WO).

\section{ELECTRIC POWER QUALITY}

Although utilities keep on trying to improve the reliability of the grid, sensitivity of industrial equipment to power quality disturbances increases as automation and electronics become more ubiquitous in industry.

Typically, industrial equipment complies with sensitivity curves as the one defined by IEEE 446 standard Figure 3 or others similar [8]. Unfortunately, it is known that electrical networks cannot guarantee these thresholds in a continuous way.

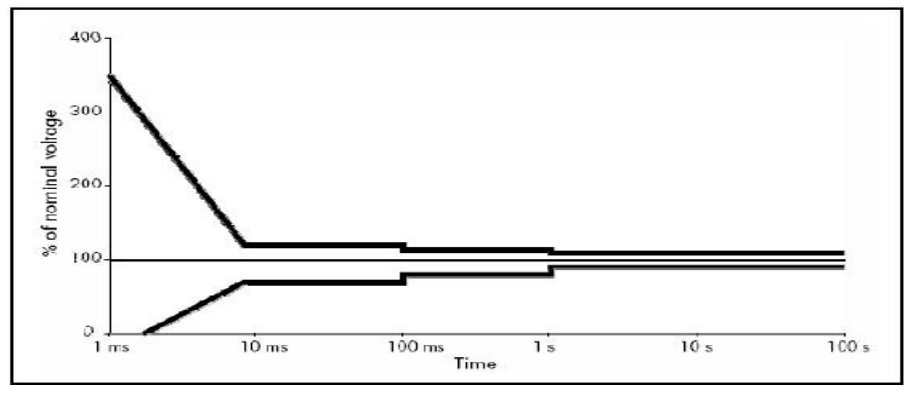

Figure 3. IEEE 466 standard for equipment sensitivity

\subsection{Voltage Sag}

A voltage sag is a voltage drop from $10 \%$ to $90 \%$ of the face value for one duration of $10 \mathrm{~ms}$ to $1 \mathrm{mn}$ [IEEE Std.1159], so that the short cut represents a voltage drop higher than $90 \%$ of the face value and a duration of $10 \mathrm{~ms}$ to $1 \mathrm{mn}$ as shown in Figure 4 [9].

Int J Pow Elec \& Dri Syst, Vol. 10, No. 1, March 2019: $330-341$ 


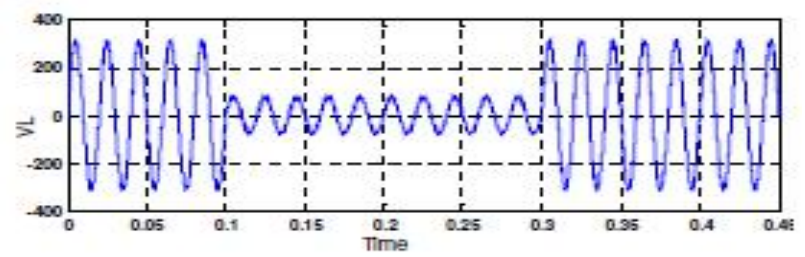

Figure 4. Voltage sag

\subsection{Over Voltage}

Over voltages are accidental rises in voltage Figure 5 that can be caused by phenomena of atmospheric origin (Lightning), by significant load releases, faulty operations of voltage regulators, by Ferroresonance or operations on the network [9].

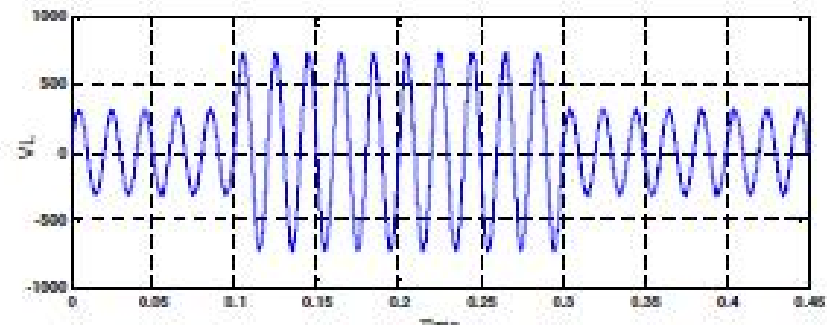

Figure 5. Over voltage

\section{OPERATING PRINCIPLE OF DVR}

A Dynamic Voltage Restorer (DVR) is a recently proposed series connected solid state device. In this case, it is normally installed in a distributed generation between the supply and the critical load feeder. Its primary function is to rapidly boost up the load-side voltage in the event of a disturbance in order to avoid any power disruption to that load. It injects a voltage into the system in series with the distribution feeder and in synchronicity with the voltages of the distribution system to regulate the load side voltage. The injecting voltages of controllable amplitude, phase angle, and frequency (harmonic) in to the distribution feeder in instantaneous real time via a series-injection transformer as shown in Figure 6. The 'missing voltage' is the difference between the nominal voltage and the actual, it's calculated by a control system and it send to switchers of converter source converter (VSC) to inject in series in low voltage distribution systems [9].

The basic idea of a DVR is to inject the missing voltage cycles vinj ( $\mathrm{t}$ ) into the system through series injection transformer whenever voltage sags/swells are present in the system supply voltage. As a consequence, sag and swell are unseen by the loads. During normal operation, the capacitor receives energy from the energy storage systems. When voltage sags or swells are detected such as in Figure 6, the capacitor delivers DC supply to the converter (VSC). The VSC ensures that only the missing voltage is injected to the transformer to improvement the voltage of sensitive load [9].

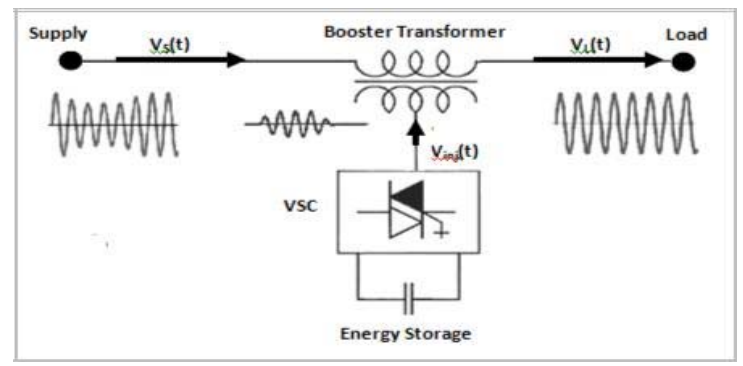

Figure 6. Typical schematic of a power system compensated by DVR

Power quality enhancement by using d-facts systems applied to distributed generation (S. A. Zegnoun) 
A relatively small capacitor is present on dc side of the PWM solid state inverter and the voltage over this capacitor is kept constant by exchanging energy with the energy storage reservoir.

The required output voltage is obtained by using pulse-width modulation switching pattern. As the controller will have to supply active as well as reactive power, some kind of energy storage is needed. In the DVRs that are commercially available now, large capacitors are used as a source of energy. Other potential sources are being considered are: battery banks, superconducting coils, and flywheels.

Figure 7 show a simplified single-line diagram of compensation strategy of medium voltage DVR for voltage sag. During the fault condition, medium voltage DVR will inject both active and reactive power and make appropriate voltage and current compensation [9], [10].

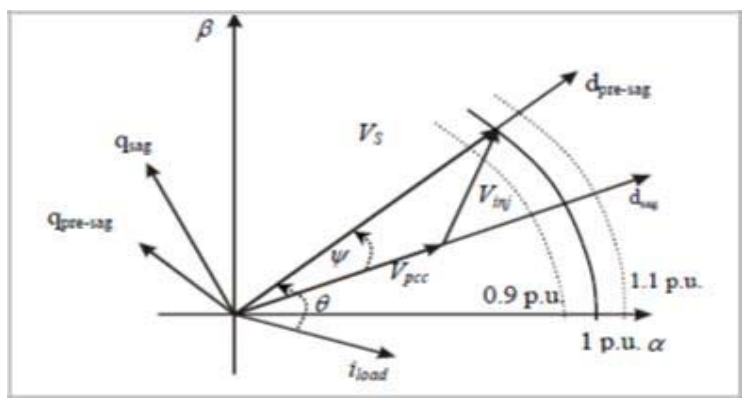

Figure 7. Compensation strategy of DVR for voltage sags

This will thus restore both magnitude and phase of the load voltage. Assuming that load voltage and current in pre-fault conditions are both equal to 1 p.u., the power injected by DVR during voltage sag/swell mitigation is equal to:

$$
\begin{aligned}
& \bar{S}_{\text {in } j}=\bar{V}_{\text {in } j} \bar{I}_{\text {load }}=\left(\bar{V}_{\text {load }} \bar{V}_{x}\right) \bar{I}_{\text {load }}=\left(1 \cdot V_{x} e^{j \Psi}\right) e^{j \theta} \\
& \cos \theta+j \sin \theta-\left(V_{x} \cos (\theta+\psi)+j V_{x} \sin (\theta+)\right)
\end{aligned}
$$
given by

Where $\psi$ is phase shift angle and $\theta$ is power factor angle. Observe that power absorbed by the load is

$$
\bar{S}_{\text {load }}=P_{\text {load }}+j Q_{\text {load }}=\bar{V}_{\text {load }} \bar{I}_{\text {load }}=e^{j \theta}=\cos \theta+j \sin \theta
$$

Where Vload is $1\left\llcorner 0^{\circ}\right.$ and I*load is ej $\theta$, therefore, the active and reactive power injected by DVR is given by (3) and (4), respectively

$$
\begin{aligned}
P_{\text {inj }} & =\left[1 . \frac{V_{x s a g} \cos (\theta+\psi)}{\cos \theta}\right] P_{\text {load }} \\
Q_{\text {inj }} & =\left[1 \cdot \frac{V_{\text {xsag }} \sin (\theta+\psi)}{\sin \theta}\right] Q_{\text {load }}
\end{aligned}
$$

\section{WIND MODEL}

Wind energy is transformed into mechanical energy by means of a wind turbine whose rotation is transmitted to the generator by means of a mechanical drive train [12].

The power produced by a wind turbine is a function of the wind speed input to the system. In general, the minimum wind speed for generation of power is $4 \mathrm{~m} / \mathrm{s}$ and a maximum of $18 \mathrm{~m} / \mathrm{s}$. The mechanical power produced by a wind turbine is given by the following equation.

$$
p=\frac{1}{2} \rho \pi r^{2} v^{3} C_{p}(\lambda . \beta)
$$




$$
\begin{aligned}
& C_{p}(\lambda . \beta)=\frac{1}{2}\left(\Gamma-0.0022 \beta^{2}-5.6\right) e^{-0.17 \Gamma} \\
& \lambda=\frac{w . r}{V} \\
& \Gamma=\frac{r_{.}(3600)}{\lambda \cdot(1609)}
\end{aligned}
$$

Where, $\mathrm{Pt}$ is the extracted power from the wind, $\rho$ is the air density $[\mathrm{kg} / \mathrm{m} 3], \mathrm{r}$ is the turbine radius $[\mathrm{m}], v$ is the wind speed $[\mathrm{m} / \mathrm{s}], \beta$ is blade pitch angle $[\mathrm{deg}], \mathrm{w}$ is the rotational speed $[\mathrm{rad} / \mathrm{s}]$ and $\mathrm{Cp}$ is the turbine power coefficient which represents the power conversion efficiency and it is a function of the ratio of the rotor tip-speed to the wind speed.

The torque coefficient and the turbine torque are expressed as follows:

$$
\begin{aligned}
& C_{t}=\frac{C_{p} \cdot(\lambda)}{\lambda} \\
& T_{M}=\frac{1}{2} \rho C_{t}(\lambda) \pi r^{3} V^{2}
\end{aligned}
$$

Where, $\lambda$ is tip speed ratio, TM is the wind turbine output torque [Nm]. Figure 8 depicts a variable speed wind energy conversion system. The electrical generator popularly employed for partially variable speed wind energy conversion systems are doubly fed induction generators [13], [14].

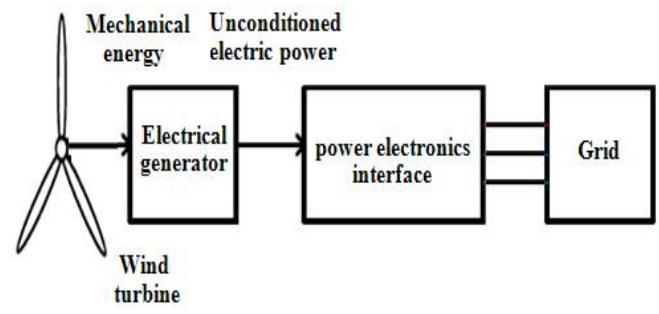

Figure 8. Variable speed of wind energy conversion system

Many studies have been made on the speed control part and on ways to reduce the cost of the unit. There are several types of inverters which are used on wind turbine installations, such as PWM-VSI converters and matrix converters. However, the PWM-VSI converter is widely used. The back to back PWMVSI is a bi-directional power converter consisting of two PWM-VSI inverters. The topology of this inverter is shown in Figure 9.

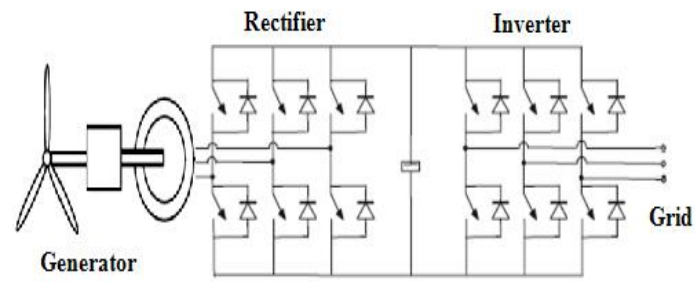

Figure 9. Topology of wind power generation system using Three-Phase Boost Rectifier

To achieve full control of the grid current, the DC link voltage must be boosted to a level higher than the amplitude of the grid line voltage. The power flow of the grid side converter is controlled in order to

Power quality enhancement by using d-facts systems applied to distributed generation (S. A. Zegnoun) 
keep the DC-link voltage constant, while the control of the generator is set to suit the magnetization demand and the reference speed. [15]. The voltage and torque equations of a no salient permanent magnet generator in the rotor reference frame can be written as follows:

$$
P\left[\begin{array}{l}
i_{d} \\
i_{q}
\end{array}\right]=\left[\begin{array}{cc}
-\frac{R_{s}}{L_{s}} & \omega_{r} \\
-\omega_{r} & -\frac{R_{s}}{L_{s}}
\end{array}\right]\left[\begin{array}{l}
i_{d} \\
i_{q}
\end{array}\right]+\frac{1}{L_{s}}\left[\begin{array}{c}
-V_{d} \\
-V_{q}+\omega_{r} \lambda_{m}^{\prime}
\end{array}\right]
$$

Where:

$$
\begin{aligned}
& {\left[\begin{array}{l}
i_{d} \\
i_{q}
\end{array}\right]=A \frac{1}{L_{s}}\left[\begin{array}{c}
-V_{d} \\
-V_{q}+\omega_{r} \lambda_{m}^{\prime}
\end{array}\right]} \\
& A=\left(\left[\begin{array}{l}
P \\
Q
\end{array}\right]-\left[\begin{array}{cc}
-\frac{R_{s}}{L_{s}} & \omega_{r} \\
-\omega_{r} & -\frac{R_{s}}{L_{s}}
\end{array}\right]\right)^{-1} \\
& T_{e}=\left(\frac{a}{2}\right)\left(\frac{P}{2}\right) i_{q} \lambda^{\prime}{ }_{m}
\end{aligned}
$$

Adding wind power to power systems will have beneficial impacts by reducing the emissions of electricity production and reducing the operational costs of the power system as less fuel is consumed in conventional power plants. Wind power will also have a capacity value to a power system.

However, possible negative impacts will have to be assessed to make sure that they will not offset too large a part of the benefits and also to ensure the security of the power system operation. The limited predictability and high inter-temporal variations of wind power cause a full spectrum of problems, ranging from shorter term frequency deviations to longer term balancing problems and involves a series of new challenges and additional constraints for the operation on the electricity grid. [16].

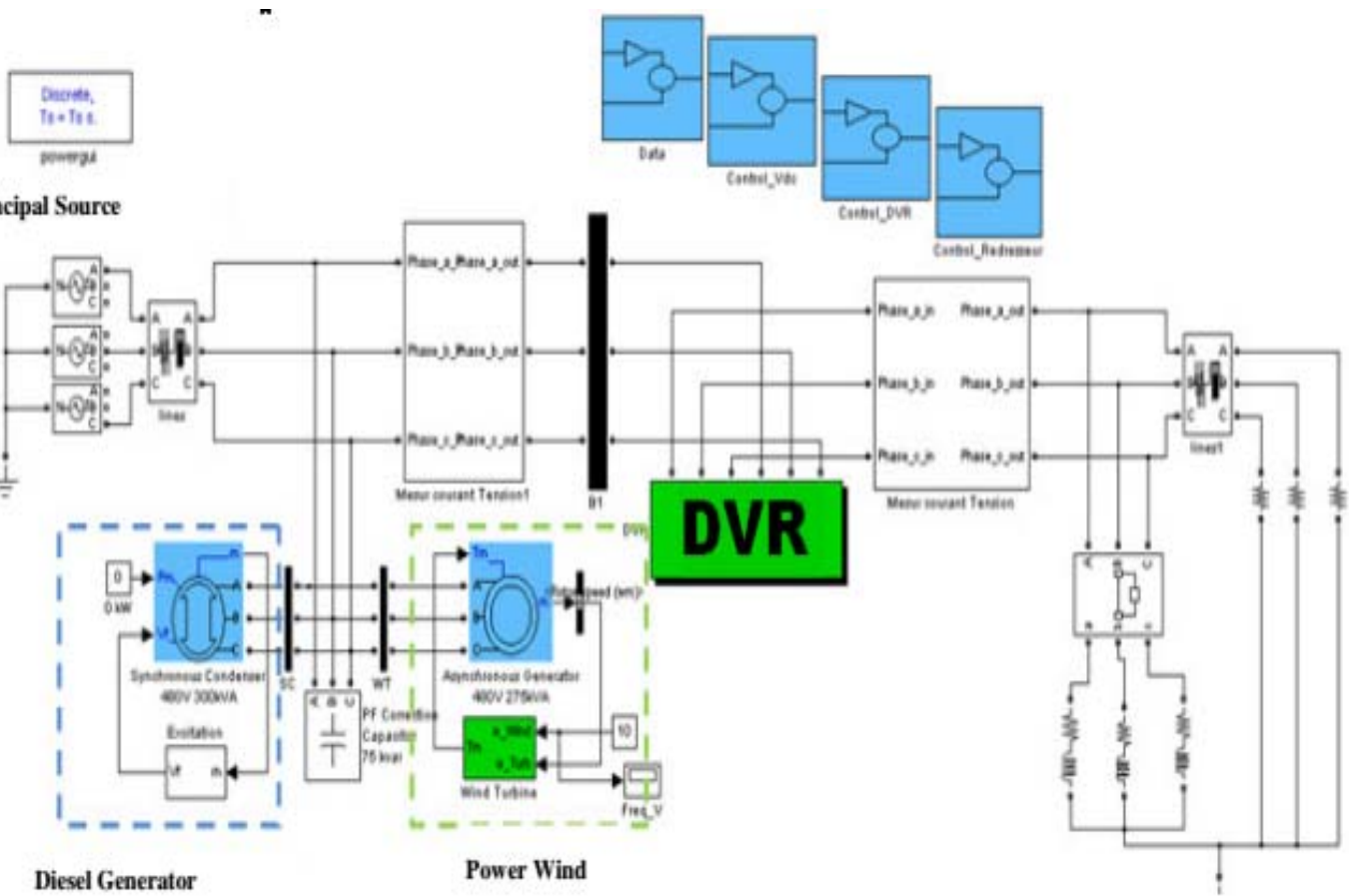

Figure 10. Circuit diagram of wind diesel hybrid system in matlab/simuling 


\section{SIMULATION RESULTS}

The circuit diagram employed for modeling medium penetration WDHS is shown in Figure 10 and it has been simulated using Matlab/Simulink. The performance of the system has been considered with the parameters of deferent principal component of this model in presented in the following table.

The wind generation system is modeled as an asynchronous generator connected to a wind turbine block, customized from Matlab/Simulink library. The generator model of wind turbine is an Induction generator (IG) when we integrated a six (06) of $1.5 \mathrm{MW}$ in transmission network of $30 \mathrm{Kv}$.

The performance of the DVR for different supply disturbances is tested under various operating conditions. Several simulations of the DVR with proposed controller scheme and new configuration of it have been made.

The problems due to the large-scale integration of wind power plants into power system increase the difficulty to participate in the system services and to stabilize the electrical grid strongly dependent of the supply-demand balance.

Table 1. principal parameters of DVR

\begin{tabular}{|c|c|}
\hline parameters & Details \\
\hline \multirow{5}{*}{$\begin{array}{l}\text { DVR } \\
\text { systems }\end{array}$} & $\mathrm{V}=380 \mathrm{~V} / f=50 \mathrm{~Hz}$ \\
\hline & $\mathrm{P}=8 \mathrm{kw} / \mathrm{Q}=700 \mathrm{VAR}$ \\
\hline & $V d c=735.603 \mathrm{~V}$ \\
\hline & $\begin{array}{l}\mathrm{Rs} / \mathrm{Ls} / \mathrm{Cs}=0.002 \Omega, 14.81 \mathrm{mH}, 0.52773 \\
\mu \mathrm{F}\end{array}$ \\
\hline & $K i=0.1462$ and $K p=52.3734$ \\
\hline \multirow{4}{*}{$\begin{array}{l}\text { Wind } \\
\text { turbine }\end{array}$} & $\mathrm{V}_{\text {out }}=575 \mathrm{~V} / f=50 \mathrm{~Hz}$ \\
\hline & $\mathbf{P}=\mathbf{3} \mathbf{M w}$ \\
\hline & $\begin{array}{c}\text { Rs (p.u) } \\
0.004843 / 0.1278,0.004377 / 0.1791 \\
\text { Ls (p.u) }\end{array}$ \\
\hline & $\begin{array}{c}\Gamma_{\mathbf{L}}=\mathbf{6 . 7 7}, / C_{i}=5.04 \quad / \mathbf{F}_{\mathrm{F}}=0.01 \text { in }(\mathbf{p . u}) \\
\mathrm{Np}=3\end{array}$ \\
\hline \multirow{2}{*}{$\begin{array}{l}\text { Diesel } \\
\text { generator }\end{array}$} & $\begin{array}{l}\mathbf{V}_{\text {out }}=\mathbf{5 k V}, / \boldsymbol{f}=\mathbf{5 0 H z} \\
\mathrm{P}=2 \mathrm{MW} \text { and } \mathrm{Q}=500 \mathrm{VAR}\end{array}$ \\
\hline & $\begin{array}{l}\text { Vdc }=45 \mathrm{~V}, / \text { Rst }=0.0036 \text { (p.u) } \\
\mathrm{Np}=2\end{array}$ \\
\hline
\end{tabular}

When diesel systems are used as distributed generators running in parallel with the power network, power quality issues are believed to be insignificant to cause any problems. The understand the power quality issues due to interaction of diesel systems with other source of renewable energy as a wind; it is objective of this paper, when we interested in this travel on only two type of electrical disturbances as a sag and over voltage. In order to supplied power to rural or remote areas.

In this case the purpose of the diesel unit is not only to supply power, but to also be responsible for maintaining the network frequency and voltage within appropriate levels. If the responsibilities of the diesel generator are disrupted due to unpredictable wind and load conditions, then frequency and voltage-based problems may occur within the network. The voltage sags presented in hybrid systems diesel-wind is due to wind turbine startup can be approximately $15 \%$ at the diesel generator terminal with a frequency dip of 5\% before recovering to nominal values. One of the problems associated with in this system is the slow response of the power dispatching. As a result, a stable frequency may not be maintained and voltage regulation of the network may degrade. Hence, the DVR in one solution may be in the area of power dispatching control and voltage regulation.

The high sensitivity of the wind energy to the grid disturbances, such as voltage dips or over voltage, often causes a disconnection or connection of production during incidents on the grid. These faults can aggravate an imbalance between the production and the consumption. In this Section representative simulation results are included to illustrate and understand the performance of DVR under single-phase and three-phase sags and over voltage conditions. The voltage of power system was unstable, i.e. it dips where the wind power is integrated and with its penetration in power grill, or the diesel generator was started to provide the power electrical in power systems considered. The second fault, swell voltage is created by disconnection the wind of the systems WDHS in case when the speed of wind is exceeding the range of safe operation, or, in case when the diesel generator is stopped.

A DVR was used to stabilized the voltage electrical charged by loads connection in Point of Common Coupling (PCC) of the supply systems contains the IG wind and diesel generator integrating in infinite bus with classical source. A DVR is connected to the system through a series transformer with a rapport transformation equal to $1: 1$. A DVR is based on three phase voltage PWM inverter with LC output filter to remove high frequency voltage components. An R-L load $(\mathrm{R}=10 \Omega, \mathrm{L}=10-6 \mathrm{H})$ is considered.

Power quality enhancement by using d-facts systems applied to distributed generation (S. A. Zegnoun) 
The results of the most important simulations are represented in Figures 11-15. A case of voltage sag and over voltage in single phase, are simulated and the results are shown in Figure 11. Figure 11(a), shows a reduction of $35 \%$ of voltage at $0.05 \mathrm{~s}$ and it is kept until $0.2 \mathrm{~s}$, with total voltage sag duration of $0.15 \mathrm{~s}$ and an over voltage presented between a $0.25 \mathrm{~s}$ and $0.4 \mathrm{~s}$, with a period at time is $0.15 \mathrm{~s}$. Observe that the DVR quickly injects the necessary voltage components to maintain the load voltage. Figure 11 (b) and (c) show the voltage injected by the DVR and the compensated load voltage, respectively. A case of voltage sag in biphases and three phases are simulated and the results are shown in Figures 12 and 13.

Figures 12 (a) and 13 (a) shows a reduction of $35 \%$ of voltage at $0.05 \mathrm{~s}$ and it is kept until $0.2 \mathrm{~s}$, with total voltage sag duration of $0.15 \mathrm{~s}$. But the Figures (b) and (c) of different Figures 12 and 13 show the voltage injected by the DVR and the compensated load voltage, respectively. It can be observed that during the fault the A-phase voltage at the PCC drops down to $20 \%$ of its nominal value, while phase to ground load voltages remain almost constant during the whole event, due to the compensating actions of the (DVR). The performance of DVR for a voltage swell condition is investigated. Here, the supply voltage swell is generated as shown in Figures 14(a) and 15(a).

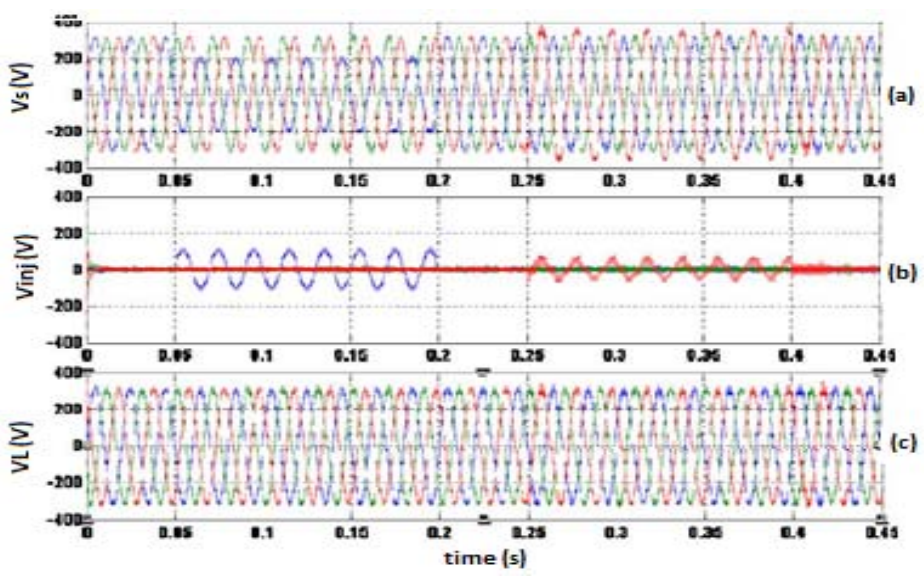

Figure 11. Sags /swells voltage compensation in single phase of system WDHS

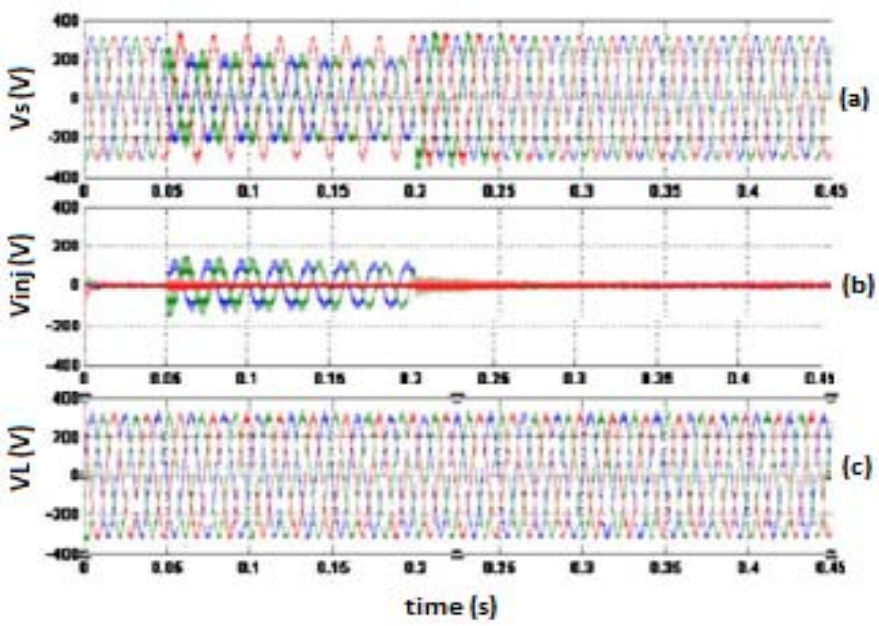

Figure 12. Sags voltage compensation in biphase system 


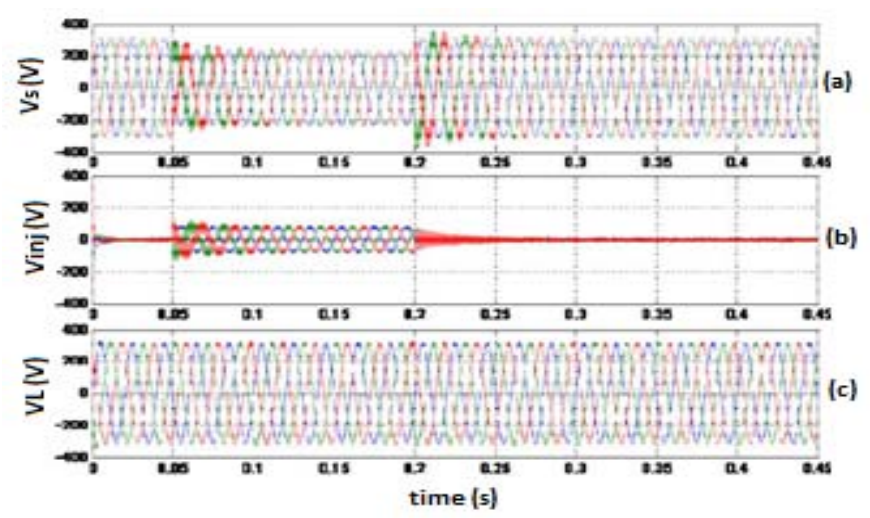

Figure 13. Sags voltage compensation in three phase system

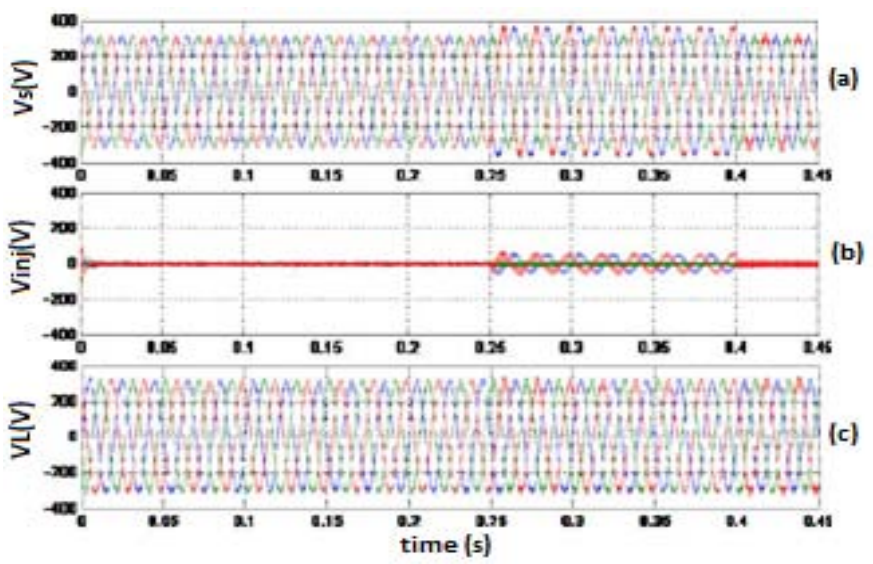

Figure 14. Compensation of two-phase overvoltage

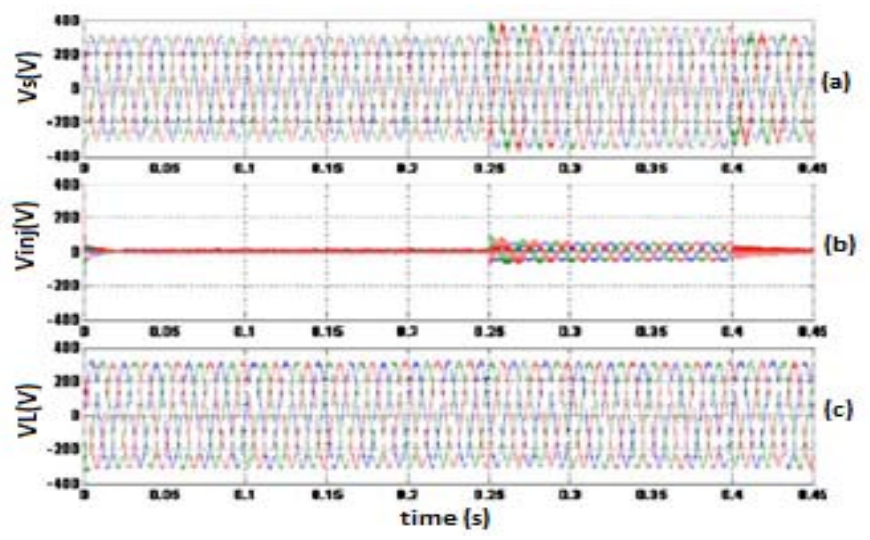

Figure 15. Compensation of three phase overvoltage

The supply voltage amplitude is increased about $120 \%$ of nominal voltage. The injected voltage that is produced by DVR in order to correct the load voltage and the load voltage are shown in Figures (b) and (c) of different Figures 14 and 15, respectively. As can be seen from the results, the load voltage is kept at the nominal value with the help of the DVR. Similar to the case of voltage sag, the DVR reacts quickly to inject the appropriate voltage component (negative voltage magnitude) to correct the supply voltage.

Power quality enhancement by using d-facts systems applied to distributed generation (S. A. Zegnoun) 


\section{CONCLUSION}

We propose in this paper a new approach of this domain by using the FACTS systems like a useful tool for mitigation of voltage unbalance in distributed generation. This proposition is for the role of improve the power quality in wind-diesel hybrid systems to protect the sensitive load caused by integrating the wind power in supply system. The simulation result in this paper shows that un-balancing of the whole system is improved.

Last decades, Renewable Energy Sources (RES) and their implementation as Distributed Generation (DG) have attracted a lot of attention all over the world. Both are considered to be important in improving the security of energy supplies by decreasing the dependency on imported fossil fuels and in reducing the emissions of greenhouse gases. There are no technical limits to the integration of wind power. However, as wind capacity increases, measures have to be taken to ensure that wind power variations do not reduce the reliability of power systems. Then, the penetration rate of wind energy must be limited in order to guarantee the stability of the electrical system and grid under acceptable conditions.

The various technologies used for mitigating the power electrical disturbance to the load sensitive requirements. Installing FACTS such as DVR is important to maintain controllable voltage stability between the generating units and the utility network. Dynamic compensation of voltage is an effective means of safeguarding the power quality.

In this case, the study Application of DVR emerging in wind-diesel hybrid system to compensate the voltage disturbance presented in different phasing of systems when the sag's and over's voltage are eliminates and this confirms the excellent performance of the proposed system for power quality improvement.

This paper has presented effects of the increase in wind generation and its impacts on power quality of distribution system. The power quality issues such as sags/swells voltage, is study with respect to wind generator connected to a grid. The modeling and simulation techniques of a wind power converter and connected power system had been analyzed using SIMULINK/MATLAB.

From this study it was found that voltage fluctuation occurs frequently due to synchronization problem associated with connection of wind generator to grid. Hence DVR was used to inject the power missing to maintain voltage level in limits and also eliminates power disturbance to sensitive load protect and this confirms the excellent performance of the proposed system for power quality improvement.

Based on the simulation carried out, it is clear that a DVR can tackle voltage sags when protecting sensitive loads. The DVR handled both balanced and unbalanced situations without any difficulties and injected the appropriate voltage component to correct rapidly any disturbance in the supply voltage to keep the load voltage balanced and constant at the nominal value. The DVR is considered to be an efficient solution due to its relatively low cost and small size; also, it has a fast-dynamic response.

\section{REFERENCES}

[1] Tandjaoui, C. Benachaiba, O. Abdelkhalek, B. Dennai and Y. Mouloudi, 'The Impact of Wind Power Implantation in Transmission Systems', elsevier, Energy Procedia 36, 260 - 267, 2013.

[2] P.Abirami, M. L George, "Implementation of NN Controlled DVR for Enhancing the Power Quality by Mitigating Harmonics," International Journal of Power Electronics and Drive System (IJPEDS), Vol. 9, No. 2, pp. 738-743, June 2018.

[3] Hussein Ibrahim, Mariya Dimitrova, Yvan Dutil, Daniel Rousse, Adrian Ilinca, Jean Perron, "Wind- Diesel hybrid system: energy storage system selection method," The 12th International Conference on Energy Storage, Innostock 2012.

[4] M. N. Tandjaoui, C. Benachaiba, O. Abdelkhalek, "Role of DVR in Power Quality Enhancement," CIAM'2011, Oran, Nov. 22-24, 2011.

[5] Shazly A. Mohammed, Aurelio G. Cerrada, Abdel-Moamen M. A, B. Hasanin, "Conventional Dynamic Voltage Restorer (Dvr) for Mitigation of Voltage Sag in Power Distribution Systems," IJAET, Mars 2013.

[6] M. N. Tandjaoui, C. Benachaiba, O. Abdelkhalek and M. L. Doumbia, 'Mitigation of voltage sags/swells unbalanced in low voltage distribution systems', IJSAT, Volume 1 No 6 August 2011.

[7] E. S. Raghav Chakravarthy, A. Bhargavi, K. Parkavi Kathirvelu and R. Balasubramanian, 'Analysis and Simulation of Isolated Wind Diesel Hybrid Power System', ARPN Journal of Engineering and Applied Sciences, Vol. 9, No. 7, July 2014.

[8] Mohammed Nasser Tandjaoui, A. Kechich, C. Benoudjafer, M. Habab, "Power Quality Improvement through Unified power quality conditioner (UPQC)," EEA, Vol. 61, 2013, Nr. 2.

[9] M.N. Tandjaoui, C. Benachaiba, O. Abdelkhalek, M. L. Doumbia, Y. Mouloudi, "Sensitive Loads Voltage Improvement Using Dynamic Voltage Restorer," IEEE Explor, 2011 ICEEI, Bandung, Indonesia, 17-19 July 2011.

[10] M. Maamri, M. N. Tandjaoui, T. Abdelouahed, C. Benachaiba, "Conséquences d'Intégration des éoliennes dans les réseaux électriques," 7ème ICREE, Sousse, Tunisi, 19-21 March 2013.

Int J Pow Elec \& Dri Syst, Vol. 10, No. 1, March 2019 : $330-341$ 
[11] Madan A. Sendhil, S. Balasubramanian and G. Arunkumar, "Current Status of Research on Hybrid Power Generation Systems," Research Journal of Applied Sciences, Engineering and Technology 8(14): 1684-1690, October 10, 2014.

[12] H. Becheri , I. K. Bousarhanne, A. Harrouz , H. Glaoui , T. Belbekri, "Maximum Power Point Tracking of Wind Turbine Conversion Chain Variable Speed Based on DFIG," International Journal of Power Electronics and Drive System (IJPEDS), Vol. 9, No. 2, pp. 527-535, June 2018.

[13] M. N. Tandjaoui, C. Benachaiba, O. Abdelkhalek, B. Dennai, "Renewable energy and its impact in power quality of distribution systems," 5'2012, Umm Al-Qura University, Makkah, April 16-18, 2012.

[14] M. N. Tandjaoui, A. Kechich, C. Benachaiba, B. Mrah et M. Saidi, "le Role des FACTS pour Ameliorer la Qualite de l'Energie Electriques Affectee par des Systemes a base des Energies Renouvelable," CIRE'13, Sousse, Tunisi, $21-23$ Dec 2013.

[15] M. N. Tandjaoui, C. Benachaiba, O. Abdelkhalek and C. Banoudjafar, "Role Of Power Electronics In Grid Integration Of Renewable Energy Systems," Journal of Electrical Engineering, Vol. 01, Mars 2016.

[16] H. Ibrahim a*, M. Ghandourb, M. Dimitrovaa, A. Ilincac, J. Perrond, "Integration of Wind Energy into Electricity Systems: Technical Challenges and Actual Solutions," Elsevier, Energy Procedia 6, 815-824, 2011.

[17] S. Sivakumar, P. Sathish Babu, "Design, Modeling and Hardware Implementation of Mppt Controlled Grid Connected Hybrid System with Smart Tracker and Improved Power Quality," IJIRD, Vol 2 Issue 6, pp 665-688, June, 2013.

[18] Satyam Prakash1, Vivek Mishra2, "Power Quality Improvement Based On Fuel Cell And Wind Energy Based Hybrid Dynamic Voltage Restorer," IJEEE, Vol. No. 7 Issue 02, pp. 196-205, July-December 2015. 